\title{
Crystal Structure and the Radiation-Induced Free-Radical Chain Reaction of 2-Deoxy- $\beta$-D-erythro-pentopyranose in the Solid State
}

\author{
Man Nien Schuchmann and Clemens von Sonntag* \\ Institut für Strahlenchemie im Max-Planck-Institut für Kohlenforschung, D-4330 Mülheim a. d. Ruhr \\ Yi-Hung Tsay and Carl Krüger \\ Max-Planck-Institut für Kohlenforschung, D-4330 Mülheim a. d. Ruhr
}

Z. Naturforsch. 36 b, 726-731 (1981); received February 9, 1981

Crystal Structure, 2-Deoxy- $\beta$-D-erythro-pentopyranose, Chain Reactions, Radiation Chemistry

The crystal structure of 2-deoxy- $\beta$-D-erythro-pentopyranose (1) was reexamined by $\mathrm{X}$-ray crystallographic studies. In crystalline 1 , a radiation-induced chain reaction occurs with the only product being, 2,5-dideoxy-D-erythro-pentonic acid (4). In the chain propagating step leading to 4 , an $\mathrm{H}$ atom is transferred over a distance of $\leq 3.3 \AA$ as taken from interatomic distances in the unperturbed crystal. The crystal structure clearly indicates the direction by which the chain reaction proceeds through the crystal. The strong temperature dependence of $\mathrm{G}(4)$ is discussed in terms of temperature effects on chain initiation, propagation and termination rates.

\section{Introduction}

Ionizing radiation is the most powerful means in creating free radicals within a crystal without disturbing the overall crystal structure (e.g. reaction (1)). Depending on the reactivity of the radicals, the substrate, and the crystal structure, a chain reaction may set in. In the carbohydrate series the first two requirements are generally met by aldoses, because the primary radicals at $\mathrm{Cl}$ commonly undergo rearrangements such as reaction (2) (cf. ref. [1]).

The resulting radical 3 is a better $\mathrm{H}$-abstracting radical than radicals of the type 2 and can propagate a chain (reaction (3)) if $\mathrm{Hl}$ of a neighbouring molecule is in sufficiently close proximity. This last requirement appears to be not generally met (cf. ref. [2]). Only $a$-lactose monohydrate [3-6] (but not anhydrous $\alpha$-lactose or $\beta$-lactose) and 2-deoxy- $\beta$-Derythro-pentopyranose (1) [1] so far show chain reactions with the above type of radical rearrangement.

Correspondence concerning the radiation chemical part should be directed to Prof. Dr. C. v. Sonntag, Institut für Strahlenchemie im Max-Planck-Institut für Kohlenforschung, Stiftstraße 34-36, D-4330 Mülheim a.d. Ruhr, concerning the crystallographic part to Prof. Dr. C. Krüger, Max-Planck-Institut für Kohlenforschung, Kaiser-Wilhelm-Platz 1, D.4330 Mülheim a. d. Ruhr.

* Reprint requests to Prof. Dr. C. von Sonntag. 0340-5087/81/0600-0726/\$01.00/0

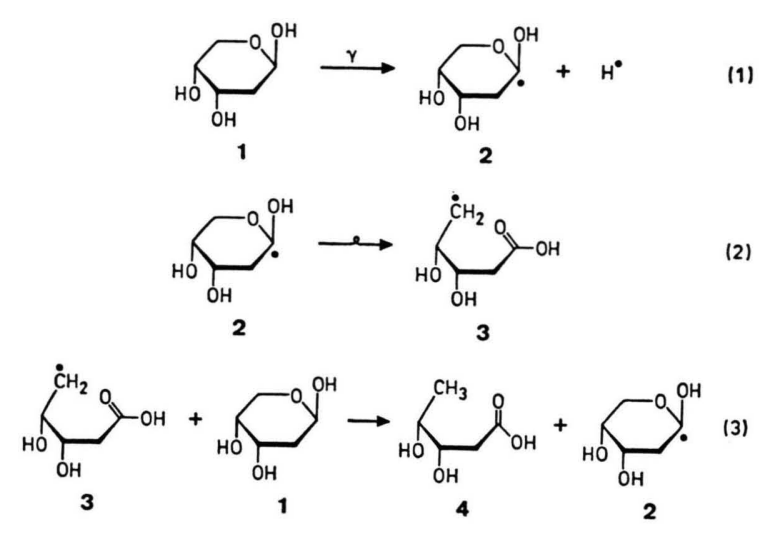

Chain reactions resulting from other types of radical rearrangement different from reaction (2) have been observed in crystalline $\alpha$-lactose monohydrate $[5,6]$ and $\beta$-D-fructopyranose [7]. The underlying principles are nevertheless similar.

The chain reaction occurring in 2 -deoxy- $\beta$-Derythro-pentopyranose [1] is the most efficient in the carbohydrate series and is free of variable modes of chain propagation as in the case of $a$-lactose monohydrate [5]. The only major degradation product observed in 1 has been identified as 2,5-dideoxy-D. erythro-pentonic acid (4) with an initial $G$ value $>650$ [1]. Such a remarkable efficiency of chain propagation invites a closer examination of the structure of crystalline 2 -deoxy- $\beta$-D-erythro-pentopyranose for the explanation. 


\section{Results and Discussion}

\section{a) Crystallography}

In view of the solid state radiation chemistry of 2 -deoxy- $\beta$-D-erythro-pentopyranose (1) we reexamined (cf. ref. [8]) its crystal structure. $\mathbf{1}$ crystallizes in the orthorhombic system, space group $\mathrm{P} 2_{1} 2_{1} 2_{1}$. Cell data with standard deviations as determined by least-squares-treatment of $\theta$-values of 49 general reflections (diffractometer data) are given in Table I.

One octant of intensity data was collected from a single crystal mounted on a Siemens-Hoppe

Table I. Cell data of 2-deoxy- $\beta$-D-erythro-pentopyranose.

\section{$\mathrm{C}_{5} \mathrm{H}_{10} \mathrm{O}_{4}$}

space group: $\mathrm{P} 22_{1} 2_{1} 2_{1}$

$a=11.3532(5) \AA$

$b=10.6425(4) \AA$

$c \quad=\quad 4.8687(2) \AA$

$\mathrm{V}=588.27 \AA^{3}$

$Z=4$

$\mathrm{d}_{\mathrm{calc}}=1.514 \mathrm{~g} \mathrm{~cm}^{-3}$

computer-operated diffractometer [9]. 644 unique reflections were measured by a $\theta-2 \theta$-scan technique with $\mathrm{Cu}$-radiation $(\lambda=1.5418 \AA)$. The intensities of only 9 reflections were below the statistical noise of the detector and treated subsequently as unobserved and were not included in the refinement.

The positions of the non-hydrogen atoms were determined by direct methods [10]. All hydrogen atoms were located from subsequent difference Fourier-syntheses. The model was refined by full matrix least-squares methods by minimizing the quantity $\left[\Sigma \mathrm{w}\left(\left|\mathrm{F}_{\mathrm{o}}\right|-\left|\mathrm{F}_{\mathrm{c}}\right|\right)^{2}\right]$. The final $R$-factors are: $R=0.0490 ; R_{\mathrm{w}}=0.0782$. Atomic scattering factors for neutral $\mathrm{C}$ and $\mathrm{O}$ were taken from the tabulation of Cromer [11] while the values due to McWeeny [12] were used for hydrogen atoms. Final positional parameters are listed in Table II.

The perspective drawing of the molecule $\mathrm{C}_{5} \mathrm{H}_{10} \mathrm{O}_{4}$ together with the standard numbering scheme for carbohydrates and pertinent geometrical data are given in Fig. 1. A projection of the cell content is shown in Fig. 2. Standard deviations are 0.003 to $0.004 \AA$ for the bond lengths and $0.2^{\circ}$ for the bond angles. The molecule adopts the chair conformation with hydroxyl groups at $\mathrm{Cl}$ and $\mathrm{C} 4$ being at axial positions and that attached to $\mathrm{C} 3$ in equatorial position. As such, the structure is similar to that elucidated previously from projections with limited data sets [8]. The orientation of the molecules in the unit cell, however, differs substantially. The mole-

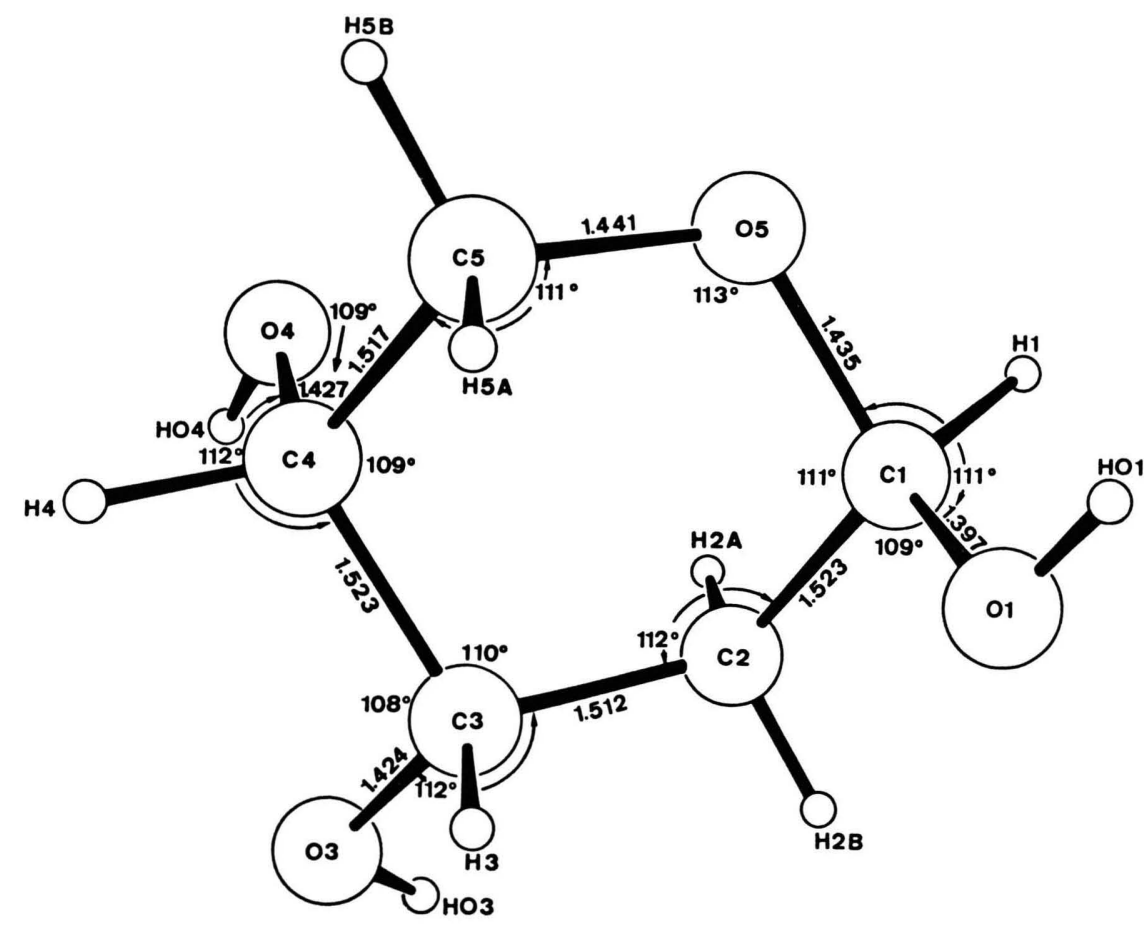

Fig. 1. Perspective drawing of the molecule 2 -deoxy- $\beta$-D. erythro-pentopyranose. 


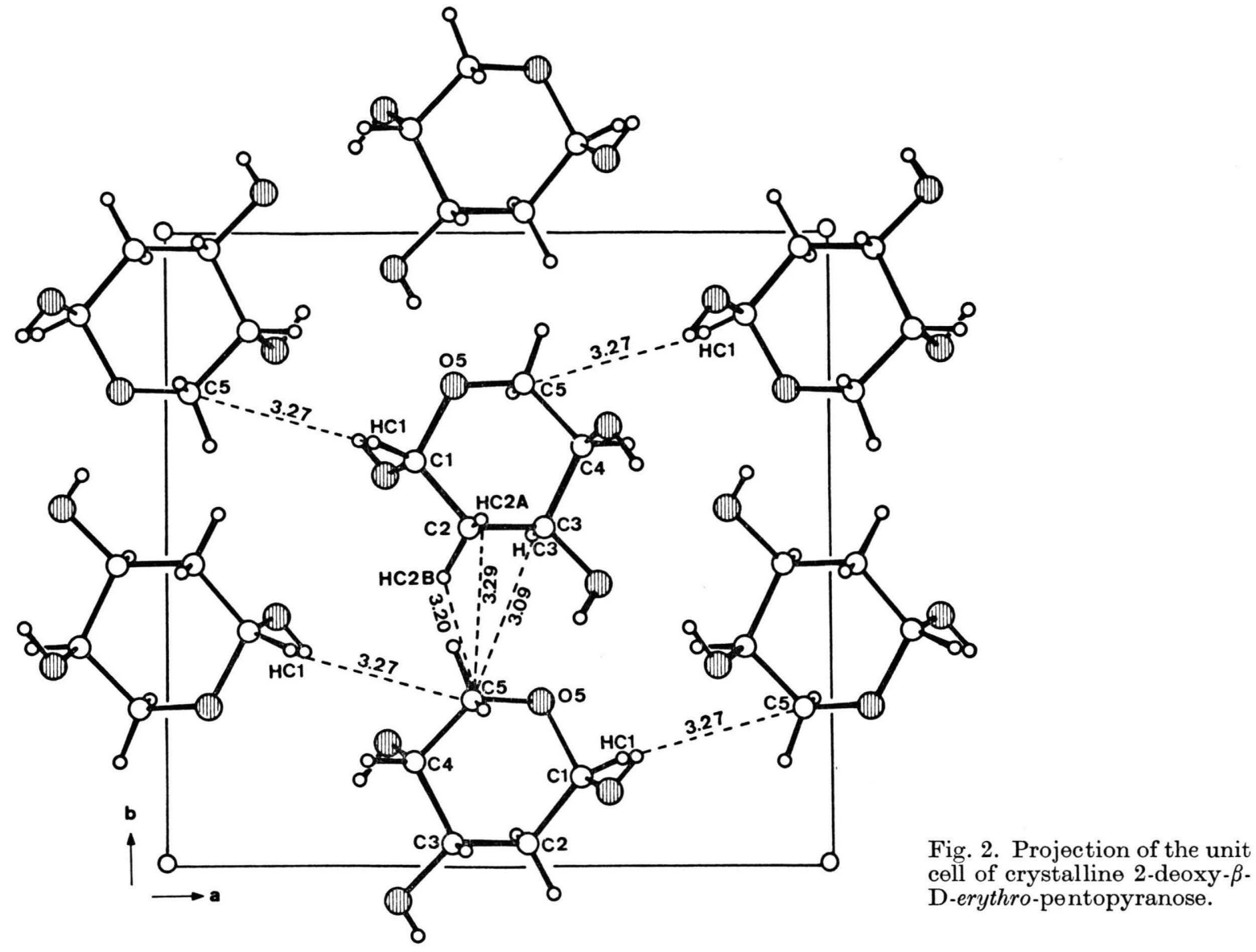

cules in the crystal interact through a hydrogen bonding network. Typical interactions are

Table II. Atomic positional parameters with standard deviations $(\times 1000)$.

\begin{tabular}{llrl}
\hline Atom & $x$ & $y$ & $z$ \\
\hline O1 & $6675(1)$ & $-1113(1)$ & $2917(5)$ \\
O3 & $3469(1)$ & $606(1)$ & $5738(5)$ \\
O4 & $3321(1)$ & $-1889(1)$ & $7609(4)$ \\
O5 & $5649(1)$ & $-2534(1)$ & $5685(5)$ \\
C1 & $6248(2)$ & $-1349(2)$ & $5558(7)$ \\
C2 & $5425(1)$ & $-287(2)$ & $6392(7)$ \\
C3 & $4292(1)$ & $-297(1)$ & $4761(6)$ \\
C4 & $3718(1)$ & $-1588(2)$ & $4907(6)$ \\
C5 & $4606(2)$ & $-2568(1)$ & $4002(7)$ \\
HO 1 & $7083(37)$ & $-1663(44)$ & $2374(99)$ \\
HO 3 & $3758(26)$ & $1140(24)$ & $6776(66)$ \\
HO4 & $2894(35)$ & $-1296(31)$ & $8504(96)$ \\
H 1 & $6874(24)$ & $-1637(33)$ & $7194(83)$ \\
H 2 A & $5252(27)$ & $-416(35)$ & $8370(94)$ \\
H 2 B & $5818(25)$ & $501(29)$ & $5926(91)$ \\
H3 & $4471(23)$ & $-172(33)$ & $2782(99)$ \\
H4 & $3015(20)$ & $-1602(25)$ & $3565(64)$ \\
H5A & $4769(26)$ & $-2418(27)$ & $1882(94)$ \\
H5B & $4307(32)$ & $-3400(33)$ & $3700(99)$ \\
\hline
\end{tabular}

$\mathrm{O}^{\prime} \cdots \mathrm{H} 1-\mathrm{O} 1, \quad \mathrm{O}^{\prime} \cdots \mathrm{H} 4-\mathrm{O} 4$ and $\mathrm{O}^{\prime} \cdots \mathrm{H} 3-03$. These intermolecular contacts are in the range of 2.0-2.2 \&. Other intermolecular contacts relevant to the solid state radiation chemistry described below are given in Fig. 2 .

\section{b) Radiation chemistry}

The nature of the chain reaction product (4) demands that in the propagating step the radical centered at C5 (3 from reaction (2)) must abstract $\mathrm{Hl}$ of a neighbouring 2-deoxy- $\beta$-D-erythro-pentopyranose molecule (reaction (3)). However, in Fig. 2 it can be seen that from a radical site at $\mathrm{C} 5, \mathrm{H} 1$ from a next molecule is by no means the closest available $\mathrm{H}$ atom. Besides $\mathrm{H} l$ there are three other carbon-bound $\mathrm{H}$ atoms, all with their distance to C5 $\leq 3.3 \AA$. Thus intermolecular distance cannot be the only factor determining the propagating step (for even longer $\mathrm{H}$ transfer distances within a crystal matrix, see ref. [13]). One will have to consider that abstraction of $\mathrm{Hl}$ is activated by two oxygen 
functions $(\mathrm{Ol}$ and $\mathrm{O5})$ whereas $\mathrm{H} 3$ is only activated by one (O3). The two hydrogen atoms bound to $\mathrm{C} 2$ are not activated by oxygen functions and may be disregarded as potential sites for this reason. Besides, the unperturbed situation as shown by the crystal structure must not necessarily reflect the true positions of the various atoms involved in the course of the reaction. In radical 3 the single bond between $\mathrm{C} 1$ and $\mathrm{O} 5$ is replaced by a double bond. Thereby the ring structure is broken, an effect which could allow movements not possible with the ring-closed molecule. A combination of the above effects could favour the abstraction of $\mathrm{Hl}$ (reaction (3)) rather than another nearby $\mathrm{H}$ atom.

A similarity can be found in the $\beta$-D-fructopyranose system [7] where a nearby $\mathrm{H}$ atom (3.4 $\AA)$ is transferred in the chain propagating step. This $\mathrm{H}$ atom, however, is not the very nearest from the radical site. There is another albeit less activated $\mathrm{H}$ atom in closer proximity. The abstraction of the latter was thought to cause chain termination, especially at low temperatures. At $0{ }^{\circ} \mathrm{C}$ the chain reaction comes nearly to a halt.

To see if the chain reaction in crystalline 2-deoxy$\beta$-D-erythro-pentopyranose (1) also shows similar temperature dependence, we have measured the yields of the only major product 2,5-dideoxy-D. erythro-pentonic acid (4) at various temperatures. The results are given in Fig. 3 . There it is shown that G (4) strongly decreases on lowering the temperature. The factors responsible for the lower yields of 4 at low temperatures can be:

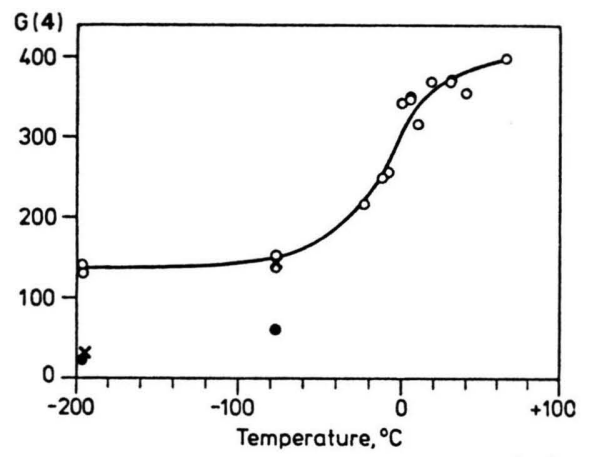

Fig. 3. Temperature dependence of the $G$ value of 2,5-dideoxy-D-erythro-pentonic acid (4).

Dose : $1.7 \cdot 10^{19} \mathrm{eV} \mathrm{g-1}$. Open circles: samples allowed to come to room temperature slowly after irradiation. Closed circles: samples dissolved in water immediately after irradiation. $\mathrm{x}$ : samples kept at irradiation temperature for $5 \mathrm{~h}\left(-77^{\circ} \mathrm{C}\right)$ or 3 days $\left(-196^{\circ} \mathrm{C}\right)$ after irradiation. i. Lower initiation rates. The initiation step, in which radical $\mathbf{2}$ is formed either by the direct action of radiation (reaction (1)) or as the result of the abstraction of $\mathrm{Hl}$ by an $\mathrm{H}$ atom (reaction (4)), can be temperature dependent.

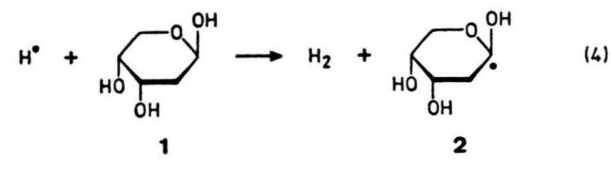

Although the $\mathrm{H}$ atom can in principle abstract some other carbon-bound $\mathrm{H}$ atoms. $\mathrm{H} \mathrm{l}$ might be a preferred site of attack (cf. also ref. [14]). Since $\mathrm{H}_{2}$ is formed in reaction (4), (among other possible paths not leading to chain initiation) $\mathrm{G}\left(\mathrm{H}_{2}\right)$ is an approximate measure of the initiation rate. Indeed, $\mathrm{G}\left(\mathrm{H}_{2}\right)$ was found to increase from 2.4 at $-196{ }^{\circ} \mathrm{C}$ to 3.5 at $20^{\circ} \mathrm{C}\left[\mathrm{G}\left(\mathrm{H}_{2}\right)=3.0\right.$ at $-77^{\circ} \mathrm{C} ; \mathrm{G}\left(\mathrm{H}_{2}\right)=3.1$ at $-20{ }^{\circ} \mathrm{C}$; errors $\left.\left.\pm 15 \%\right)\right]$.

The above results indicate that the drop in $\mathrm{G}(\mathbf{4})$ with temperature (from $\sim 370$ at $20^{\circ} \mathrm{C}$ to 140 at $-97{ }^{\circ} \mathrm{C}$, see Fig. 3) is to a considerable extent connected with a drop in $G(2)$, since in these experiments the chain reaction, once started, was allowed to proceed under the same temperature conditions. A low $\mathrm{G}(2)$ could be the consequence of slower rates of reactions (1) and (4) and hence a higher probability of the recombination of radical 2 with a (caged) $\mathrm{H}$ atom (reaction (5)) at low temperatures. This would remove up to two (considering reaction (4)) initiating radicals. $\mathrm{H}$ atom scavenging by any other radical would also reduce $\mathrm{G}(\mathbf{4})$.

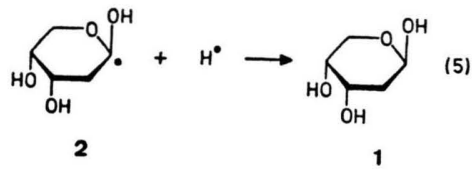

ii. Slower propagating rates. The propagation of the chain reaction in $\mathbf{1}$ involves both radical rearrangement (reaction (2)) and $\mathrm{H}$ abstraction (reaction (3)). Both of these reactions as well as the diffusion of $\mathrm{H}$ atoms in the crystals require certain (not negligible) activation energies and are therefore less facile at low temperatures. However, radicals (i.e. 2 and $\mathrm{H}^{\cdot}$ ) induced in the crystals at low temperatures, if not efficiently removed by some chain termination mechanism such as radical combination (e.g. reaction (5)), will be trapped there and can 
propagate a chain later when the crystals are allowed to warm up to room temperature. Under such conditions the ,apparent' $\mathrm{G}(4)$ values (e.g. 140 at $-196^{\circ} \mathrm{C}$ ) are considerably higher than the corresponding values when post-irradiation propagation is quenched in samples immediately dissolved in warm water (e.g. $\mathrm{G}(4)=29$ at $\left.-196^{\circ} \mathrm{C}\right)$. At $-77^{\circ} \mathrm{C}$, post-irradiation propagation can still occur even though not as fast as at room temperature. Given sufficient time $\left(5 \mathrm{~h}\right.$ at $-77^{\circ} \mathrm{C}$, no kinetic studies done), the ultimate yield can be reached. Whereas in samples kept at $-196{ }^{\circ} \mathrm{C}$ for 3 days after irradiation, no apparent enhancement in the yield of 4 was observed. The residual value of $G(\mathbf{4})$ under such conditions is probably not the true value at $-196{ }^{\circ} \mathrm{C}$ but the result of short chains which got underway while the crystals were being warmed up upon dissolving in water.

iii. More efficient termination mechanism. One possibility for the chain reaction in $\mathbf{1}$ to terminate is when the propagating radical 3 abstracts a ,wrong' $\mathrm{H}$ atom (other than $\mathrm{H} \mathrm{l}$ ) from a neighbouring substrate molecule. The combination of a propagating radical (either 2 or 3 ) with a mobile entity like the $\mathrm{H}$ atom will also lead to chain termination. A third possibility for termination is that the propagating radical $\mathbf{3}$ reacts with a product molecule $\mathbf{4}$ formed in the preceding step (reaction (6)).

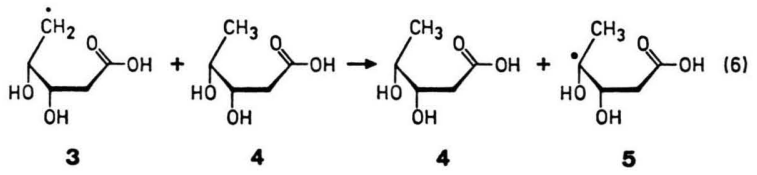

Evidence for the presence of radical 5 as a long-lived species has been provided by ESR studies $[15,16]$. In reaction (6) for the radical site at $\mathrm{C} 5$ to abstract $\mathrm{H} 4$ of a neighbouring product molecule 4 the distance required in the unperturbed crystal is $4.12 \AA$, a distance compared rather unfavourably to the shorter distances $(<3.3 \AA)$ towards the other abstractable $\mathrm{H}$ atoms discussed above (see Fig. 2). However, as both 3 and 4 are transformed from their cyclic precursors to open-chain structures, the local geometry could be so altered that the $\mathrm{C} 5-\mathrm{H} 4$ distance is no longer unfavourable. An alternative of reaction 6 would be an intramolecular 1,2 $\mathrm{H}$-shift which transforms $\mathbf{3}$ directly to $\mathbf{5}$, although, a $1,2 \mathrm{H}$-shift is considered rather unlikely [17].
Based only on the crystal structure of $\mathbf{1}$ in the unperturbed state, it is not easy to assess the effect of temperature on the first and third termination mechanisms. The abstraction of any $\mathrm{H}$ other than $\mathrm{H} l$ (termination) clearly requires higher activation energies than the abstraction of $\mathrm{Hl}$ (propagation). However, termination can compete successfully at low temperatures with propagation if the former can be assisted by tunnelling effect to overcome the energy barriers better than the latter. In other words, the closeness of the $\mathrm{H}$ atom to the radical site may be the only determining factor at low temperatures.

Termination of the second mode is expected to be more favourable at lower temperatures similar to that discussed under initiation rates. As temperature is lowered, the abstraction of $\mathrm{Hl}$ by the $\mathrm{H}$ atom to initiate a chain becomes more and more difficult because of the energy barrier of about $6 \mathrm{kcal} / \mathrm{mol}$. While the carbohydrate radicals are largely immobile in the crystal matrix, the $\mathrm{H}$ atom is free to diffuse to a radical site to combine with it. This latter reaction requires only the activation energy of diffusion of the $\mathrm{H}$ atom. Although here again there is the uncertainty that tunnelling effect at low temperatures might reverse the situation.

The chain reaction will most likely terminate when it reaches an imperfection in the crystal where proper propagation is difficult. In accordance with this view is the observation that $\mathrm{G}(4)$ strongly decreases with increasing dose [1], most likely because every chain creates new imperfections in the crystal matrix. Nevertheless, the efficiency remains sufficiently high to convert 2 -deoxy- $\beta$-Derythro-pentopyranose (1) into 2,5-dideoxy-Derythro-pentonic acid (4) with a yield of $19 \%$ at a dose of $1.4 \cdot 10^{21} \mathrm{eV} \mathrm{g}^{-1}$ and a dose-yield plot indicated that higher conversions are possible [1]. This method is a unique way of preparing 4 as the isolation of 4 can be easily carried out by ion exchange chromatography and the unchanged 2-deoxy-Derythro-pentose can be recovered by recrystallization.

\section{Experimental}

For the crystallographic studies a single crystal of 2-deoxy- $\beta$-D-erythro-pentopyranose was kindly supplied by Prof. Dr. J. Hüttermann, Regensburg.

Crystalline 2 -deoxy- $\beta$-D-erythro-pentopyranose (Merck) was irradiated with $60-\mathrm{Co}-\gamma$-rays at a dose 
rate of $1.4 \cdot 10^{16} \mathrm{eV} \mathrm{g}^{-1} \mathrm{~s}^{-1}$ to a total dose of $1.7 \cdot 10^{19} \mathrm{eV} \mathrm{g}^{-1}$. Irradiation temperatures were maintained by using various thermostating media or by a thermostat. Unless otherwise stated, the irradiated samples were allowed to come to room temperature slowly prior to analysis. The yields of the only major product, 2,5-dideoxy-D-erythropentonic acid (4) were determined by dissolving the irradiated samples in $\mathrm{H}_{2} \mathrm{O}$ followed by addition of an excess of $0.1 \mathrm{~N} \mathrm{NaOH}$ and back titration against $0.1 \mathrm{~N} \mathrm{HCl}$.

Hydrogen was determined by GC using a $0.85 \mathrm{~m}$ molecular sieve column operated at room temperature with a thermal conductivity detector after the samples had been dissolved in argon-saturated water immediately following irradiation (doses betwen $5 \cdot 10^{19}-1.9 \cdot 10^{20} \mathrm{eV} \mathrm{g}^{-1}$ ).

Further details of the investigations on crystal structures may be received at,,Fachinformationszentrum Energie - Physik - Mathematik - GmbH, D-7514 Eggenstein-Leopoldshafen 2 ". The Rigistry. Nr. CSD 50006, the name of the author, and the reference should be given.
[1] C. von Sonntag, K. Neuwald, and M. Dizdaroglu, Radiat. Res. 58, 1 (1974).

[2] C. von Sonntag, Adv. Carbohyd. Chem. 37, 7 (1980).

[3] N. U. Ahmed, P. J. Baugh, and G. O. Phillips, J. Chem. Soc., Perkin Trans. II 1972, 1305.

[4] T. Gejvall and G. Löfroth, Acta Chem. Scand. 27, 1108 (1973).

[5] C. von Sonntag and M. Dizdaroglu, Z. Naturforsch. $28 \mathrm{~b}, 367$ (1973).

[6] M. Dizdaroglu, C. von Sonntag, D. SchulteFrohlinde, and W. V. Dahlhoff, Liebigs Ann. Chem. 1973, 1592.

[7] M. Dizdaroglu, J. Leitich, and C. von Sonntag, Carbohyd. Res. 47, 15 (1976).

[8] S. Furberg, Acta Chem. Scand. 14, 1357 (1960).

[9] C. Krüger, J. Organomet. Chem. 22, 697 (1970).
[10] G. Sheldrick, Computer program SHELX, Univ. of Cambridge, England 1976.

[11] D. T. Cromer and J. T. Waber, Acta Crystallogr. 18, 104 (1965).

[12] R. McWeeny, Acta Crystallogr. 4, 513 (1951).

[13] M. Kikuchi, N. Leray, J. Roncin, and B. Joukoff, Chem. Phys. 12, 169 (1976).

[14] B. J. Parsons, D. Schulte-Frohlinde, and C. von Sonntag, Z. Naturforsch. 33 b, 666 (1978).

[15] J. Hüttermann and A. Müller, Z. Naturforsch. 24 b, 463 (1969).

[16] J. Hüttermann and A. Müller, Radiat. Res. 38, 248 (1969)

[17] J. W. Wilt, in J. K. Kochi (ed.): Free Radicals, Vol. I, p. 378, Wiley Interscience, New York 1973. 